\title{
Expansión Hare Krishna en contextos de crisis: resignificando la movilización social desde una perspectiva religiosa en Chile $^{1}$
}

\author{
Hare Krishna Expansion in Contexts of Crisis: Redefining \\ Social Mobilization in Chile Through a Religious Perspective
}

\author{
Luis Andrés Bahamondes González \\ Universidad Alberto Hurtado - Centro de Estudios Judaicos, Universidad de Chile \\ Nelson Marín Alarcón \\ Centro de Estudios Judaicos, Universidad de Chile
}

\section{RESUMEN}

La presente investigación se focalizará en la expansión del movimiento Hare Krishna en Santiago de Chile, analizando los discursos y mecanismos de movilización que desarrollan sus integrantes frente al escenario de agitación social vivido con la llegada del nuevo milenio. Con ello no solo se buscará vislumbrar las transformaciones internas acaecidas en el movimiento durante el último tiempo, sino además pretendemos identificar estrategias de acción social y políticas independientes frente a inquietudes o problemas sociales instalados en la agenda pública. De esta forma, analizaremos la manera como este grupo religioso se posiciona activamente en un escenario de demandas sociales y guía su accionar desde la particularidad filosófica y espiritual de su doctrina.

Palabras clave: Nuevos movimientos religiosos; Comunidad; Demandas sociales; Hare Krishna; Religiosidad.

\section{SUMMARY}

This paper focuses on the expansion of the Hare Krishna movement in Santiago, Chile, analysing mobilization discourse and mechanisms adopted in the face of the social upheavals of the new millennium. It seeks to understand not only recent internal transformation of the Hare Krishna movement, but also to identify social action strategies and independent policies concerning social issues in the public arena. We will analyse the active position the religious group has embraced in a context of growing social demands and how its actions are guided by the philosophical and spiritual conception of its doctrine.

Key words: New Religious Movements; Community; Social Demand; Hare Krishna, Religiosity.

\footnotetext{
${ }^{1}$ Esta investigación se enmarca dentro de los resultados del Proyecto FONDECYT de iniciación N. ${ }^{\circ} 11130281$ titulado: "Religiosidad en la ciudad: nuevos movimientos religiosos y demandas sociales en el Gran Santiago: 1990-2012", y ha sido posible gracias al financiamiento de la Comisión Nacional de Investigación Científica y Tecnológica (CONICYT) del Gobierno de Chile.
} 


\section{INTRODUCCIÓN}

Aunque el siglo XX fue prolífico en el desarrollo de movimientos sociales de todo orden - feministas, ecologistas, pacifistas, obreros, etc.-, a nivel global (Hobsbawm 1999), la instauración de la dictadura militar en Chile terminó por ahogar y exterminar todo intento de organización colectiva que significara realizar demandas al régimen (Garcés 2012; Gamboa y Pincheira 2009). Rápidamente los movimientos sociales fueron calificados como revolucionarios, marxistas, anti-sistema, agentes del caos, por ende enemigos del orden institucional. En base a esto, Délano (2004) sostiene que la piedra angular de la estabilidad democrática de Chile, se liga directamente con la herencia de la dictadura militar, que a través de diversas acciones represivas terminó instalando en la sociedad el miedo al cambio por varias generaciones, haciendo pervivir el statu quo.

Bajo este escenario los espacios de socialización desaparecieron o al menos se relativizaron. Las formas de organización colectivas dieron paso paulatinamente a la búsqueda de soluciones individuales socavando la constitución de redes asociativas que respondieran a la satisfacción de necesidades. Si durante el periodo 1960-1980 una de las vías de respuesta frente al problema habitacional fue la toma de terrenos, lo cual exigía un trabajo colectivo de la comunidad, este camino se vio limitado al restringirse la libertad de asociación, el miedo permanente a la represión militar, y la pérdida de una identidad social definida (González y Quintana 2004). Es así como el abandono del Estado y de la clase política, sirvió como detonante, entre muchos factores, para revitalizar la participación y ocupación del espacio público que había sido destruido por la dictadura militar de Pinochet (Délano 2004) y que bien entrada la década de los 90 comenzó paulatinamente a desarrollarse.

El fin de la primera década del siglo XXI se ha presentado como uno de los momentos más fructíferos en términos de movilización ciudadana con posterioridad al régimen dictatorial de Pinochet. En consonancia a explosiones sociales internacionales como la Primavera Árabe (2010), el Movimiento de los Indignados (2011) o la Toma de Wall Street (2011), Chile ha presenciado como buena parte de la ciudadanía ha vuelto a levantar con fuerza reivindicaciones históricas, así como nuevas demandas surgidas de las contradicciones inherentes al modelo de desarrollo imperante. El movimiento estudiantil de 2011 (heredero de las manifestaciones de estudiantes secundarios de Santiago en 2006) logró instalar, mediante la fuerza de sus masivas marchas por todo el país, el debate acerca de la calidad, el lucro y el acceso a la educación en sus distintos niveles. De forma paralela surgieron protestas en la sureña región de Aysén (2012) que interpelaron al histórico centralismo de Santiago en la administración de los recursos económicos y naturales de las regiones. Las violentas protestas en la localidad de Freirina (2012) por la contaminación emanada desde una planta de tratamiento de cerdos, las marchas sucesivas en contra del proyecto energético Hidroaysén (2011), que pretendía intervenir amplios territorios en la Patagonia, así como las oposiciones generalizadas hacia proyectos mineros como Pascua Lama en el norte chico de Chile o la termoeléctrica de Castilla, han reabierto el debate respecto del uso intensivo de los recursos naturales por parte de las grandes compañías transnacionales y el impacto que ello conlleva en las comunidades locales.

Sin lugar a dudas, estos movimientos ciudadanos representan sólo la expresión más masiva y de mayor cobertura comunicacional de los conflictos existentes. Tanto su 
simultaneidad como el gran apoyo que han recibido del resto de la población, han llevado a algunos especialistas a considerarlos como síntomas de desgaste estructural y no como meros fenómenos aislados o transitorios. Es así como nos encontraríamos frente a una crisis de legitimidad de un modelo económico y social que acumularía un malestar creciente entre los individuos (Mayol 2012). Para Gabriel Salazar, es el modelo neoliberal en su conjunto el que tanto a nivel mundial como local estaría inserto en una fase patológica. Desde la Crisis Asiática (1997) y la Crisis Subprime (2008-2009), hasta los múltiples estallidos locales de corrupción especulativa y los excesos de la mercantilización, han invadido y distorsionado las distintas funciones centrales de la vida social: educación, salud, cultura, trabajo, etc. Dentro de este escenario, como menciona Salazar,

... la ciudadanía popular ha vuelto a tantear sus propensiones autonómicas, esta vez construyendo, paso a paso, una cultura social con correlatos de propuesta alternativa (autoeducación popular, por ejemplo), precisamente sobre la base de observar críticamente todos y cada uno de los parámetros comunitarios donde hace cortocircuito la crisis general del modelo (2012:45).

Entre los nodos problemáticos que han catalizado discusiones públicas y legislativas importantes se encuentran los principios que sostienen la educación y salud pública, la explotación de recursos naturales como el cobre, la pesca o la energía, el sistema de pensiones, los derechos de los pueblos indígenas y las minorías sexuales, la necesidad de una nueva constitución política, entre otros.

Esta sería la emergencia de una nueva forma de movilización social (Tilly y Wood 2010) inspirada en las contradicciones propias del capitalismo neoliberal y amparada en las profundas transformaciones de la vida social y cultural. Nuevas demandas ciudadanas se acompañan de nuevas formas de organización y acción social, superando las tradicionales vías de participación y deliberación. A las disminuidas organizaciones partidistas y sindicales, se suceden el actuar de ONGs, agrupaciones culturales, ambientalistas, de género o reivindicación étnica, que por medio de los medios tecnológicos disponibles coordinan sus adhesiones y demandas. Estos movimientos sociales, siguiendo los planteamientos de Alain Touraine (1998), ya no se movilizarían por alusión a la nación, el Estado o el orden social, sino más bien en torno a nuevos referentes como la ecología, la identidad sexual o el localismo. Es más, tampoco se hace necesario la temporalidad a la hora de definirlos pues lo realmente distintivo radica en sus nuevas prácticas y tipos de acción (Castells 2003). Sus intereses rebasan los conflictos sociales tradicionales, entrando en la complejidad de lo cultural y lo simbólico que es donde se genera la información y los significados (Melucci 1999).

Las transformaciones sociales y culturales que condicionan estas nuevas formas de movilización abren la posibilidad de identificar nuevos actores que escapen a las tradicionales categorías ya esbozadas. Entre ellos cabe destacar la participación de nuevas agrupaciones religiosas que irrumpen en el espacio público desde la particularidad de su cosmovisión y en respuesta a las necesidades de los individuos. De esta forma se constituyen como una alternativa frente a los problemas y demandas sociales levantadas por otros grupos u organismos. La expansión de los nuevos movimientos religiosos en Chile representa uno de los fenómenos sociales más dinámicos del último tiempo (Bahamondes 2013) que no sólo cuestiona los límites de la secularización 
moderna, sino también tensiona las clásicas formas de influencia política y social ejercidas por las instituciones religiosas más tradicionales.

Entre aquellos nuevos movimientos religiosos uno de los que destaca por su dinamismo frente a las demandas ciudadanas, así como por su crecimiento en este escenario de crisis, es el movimiento Hare Krishna. Ello no resulta casual si consideramos que desde sus orígenes esta agrupación se expandió en escenarios de profundo inconformismo y agitación social. Mientras que en la década de los 60' fueron las enseñanzas de Srila Prabhupada en el seno del movimiento hippie norteamericano las que abren el vaisnavismo a occidente, es durante los 70' y 80' que el movimiento se expande a una Latinoamérica que vivía la represión de distintas dictaduras militares. Es precisamente en este contexto que en 1976 llegan en pleno periodo dictatorial a Santiago un grupo de devotos que huían de la represión del régimen de Jorge Rafael Videla en Argentina. Por medio de la instalación de pequeñas comunidades y templos se fueron haciendo lentamente un espacio entre la juventud de la época.

Dentro del actual escenario de crisis política y social, las comunidades Hare Krishna de Santiago han logrado expandirse y consolidarse en una sociedad que los observó desde su llegada con cierta desconfianza. Al natural proceso de acostumbramiento producto del paso del tiempo, mediante el cual la presencia pública de estos grupos fue percibida como un fenómeno cotidiano, es posible observar también un mayor interés tanto de las comunidades Hare Krishna por acercarse a los intereses de la sociedad civil, como de parte de los individuos externos que encuentran atractivos importantes dentro de estas comunidades. Dicho encuentro estaría mediado ya no tan sólo por el interés que despertaría la cultura milenaria de la India, sino también por el tratamiento tanto a nivel discursivo como material que se haría de las problemáticas sociales que la opinión pública valora. En base a esto se podría afirmar que los movimientos Hare Krishna se refuerzan de manera paralela a como lo hacen el resto de movimientos sociales en el ámbito civil debido a los intereses comunes que existen entre ambos, aunque traducidos en un lenguaje religioso particular y estrategias de movilización diferentes. Comprender cómo se complementan estos procesos es lo que pretender el presente artículo.

\section{METODOLOGÍA}

La presente investigación posee un enfoque cualitativo centrado en determinar los sentidos y significados (Prat 1997) que los miembros de la comunidad Hare Krishna, ubicada en el centro de Santiago de Chile ${ }^{2}$, tienen respecto a ciertas demandas sociales instaladas en la discusión pública y como se movilizan frente a ellas. Dicha comunidad fue escogida por ser en la actualidad la de mayor participación en términos numéricos y donde se concentran las principales actividades relacionadas con la religión.

Respecto a la metodología utilizada esta consistió en un acercamiento de tipo etnográfico que buscaba interiorizarnos en el funcionamiento cotidiano (Augé 2000; Cantón 2008) de la comunidad religiosa, observando sus ritos, prácticas distintivas y

${ }^{2}$ El trabajo etnográfico fue realizado en el templo principal de ISKCON en Chile ubicado en calle José Miguel Carrera № 330, esquina Grajales, comuna de Santiago. 
festividades principales durante los años 2014 y 2015. Las observaciones se realizaron con una periodicidad semanal de acuerdo al calendario de actividades establecido por el consejo directivo de ISKCON, así como las rutinas cotidianas y la participación en acciones de movilización social. Dicho trabajo de campo se concentró tanto en los espacios de culto como en aquellos lugares públicos que les permitían a los participantes de la comunidad interactuar y relacionarse con el resto de la sociedad.

Además se llevaron a cabo entrevistas en profundidad que buscaban indagar tanto en la propia experiencia de conversión religiosa, como en la construcción de su discurso en un escenario de agitación social como el vivido en la última década ${ }^{3}$. La selección de dichos individuos fue de manera teórica considerando: su nivel de participación en la comunidad, años de permanencia en el movimiento, ocupación de cargos directivos, formación educacional u oficio. En total se realizaron 23 entrevistas en profundidad de acuerdo a los criterios establecidos en la fase anual del proyecto de investigación desarrollado ${ }^{4}$.

\section{MOVILIZACIÓN SOCIAL Y EMERGENCIA DE NUEVOS MOVIMIENTOS RELIGIO- SOS (NMRs)}

Algunos trabajos ya realizados en esta materia fuera de Chile, establecen la relación entre movimientos sociales y religiosos a partir de las transformaciones que la sociedad latinoamericana fue sufriendo durante las últimas décadas (Carozzi 1993). El cuestionamiento creciente a las iglesias, la relativización de los valores, la pérdida de confianza de las instituciones, el avance de las secularización, así como las crisis sociales, políticas y económicas, repercutieron de manera profunda en la construcción de las identidades (Parker 2005; Suárez 2003; Larraín 2005; Bahamondes 2012). Todos estos factores, habrían motivado la eclosión de nuevos movimientos religiosos en la región, sin embargo, este tipo de explicaciones es relativa y solo logra dar cuenta parcialmente de un fenómeno global (Clarke, 2006). Para ejemplificar este punto, Clarke apunta al surgimiento de nuevos movimientos religiosos en África en contextos de sociedades tradicionales donde la velocidad de las transformaciones no sería el detonador de su masificación necesariamente, lo cual indicaría que en ciertas regiones el surgimientos de nuevas agrupaciones religiosas podría ser parte de su desarrollo natural, donde se producen constantes procesos de resignificación de lo sagrado.

De acuerdo a Bastian (1997) los procesos de urbanización, coincidentes con el aumento demográfico y empobrecimiento sostenido de grandes masas de población en Latinoamérica, para la década del 50, acompañaron el desarrollo de NMRs debido a que la migración campo-ciudad facilitó el intercambio de cultos, tradiciones y creencias locales para situarlas en un escenario de cambios permanente reflejado en la urbe.

\footnotetext{
${ }^{3}$ El proceso de investigación descrito, así como la aplicación de técnicas de investigación (entrevistas y observaciones) en la comunidad Hare Krishna contó con la utilización de consentimientos informados que resguardan y garantizan la privacidad de la información recabada de acuerdo a la ley vigente.

${ }^{4}$ Las entrevistas utilizadas en la redacción del presente artículo corresponden a una fracción del total realizado y fueron seleccionadas por ser aquellas que nos han permitido caracterizar el fenómeno en estudio.
} 
El caso de estudio emblemático de este escenario es el pentecostalismo, denominado también como "refugio de masas" (Lalive 1968), destacando el valor social de la religión como articulador de redes asistenciales (materiales e inmateriales) que aplacaban las penurias de grandes masas de población carenciadas (Ossa 1991). En este sentido, Bastian (1997) sostiene que la movilización religiosa que promueve el pentecostalismo se basa en tres características, pues serían: conversionistas, taumatúrgicas y milenaristas. La conversión les entregaría una identidad propia, la taumaturgia le ofrecería solución a sus problemas de salud (curación divina), y el milenarismo otorgaría esperanza de un futuro próspero. De esta forma:

La demanda social de reestructuración es tan fuerte que decenas de dirigentes carismáticos desarrollan tales empresas donde la figura central del "profeta", en el sentido del poseedor de una autoridad carismática, es determinante para su auge. La autoridad carismática del fundador facilita la fusión igualitaria de individuos anómicos, los cuales encuentran seguridad y protección en el nuevo espacio religioso que se elabora (Bastian 1997: 140-141).

Sin embargo, a nivel regional será la década de los 60 la que marcará un hito en la eclosión de NMRs enmarcándose en un contexto histórico de grandes transformaciones sociales motivadas en gran medida por la Guerra Fría. La desconfianza de las instituciones políticas, el cuestionamiento al sistema económico capitalista, el ambiente belicista, etc., sirvieron de detonantes para la promoción de nuevas agrupaciones sociales que no solo combatieran lo ya establecido, sino también, que fuesen capaces de proponer vías alternativas de desarrollo político, económico, social, y religioso, ejemplo de esto último, fue el surgimiento de la new age, la búsqueda de espiritualidad en lo ancestral y autóctono, o bien, la importación de nuevas religiones y prácticas espirituales desde oriente. De esta forma lo religioso se diversifica, experimentando

[...] una metamorfosis en la que pierde el "centro", el monopolio simbólico, de ser el discurso de "lo social", pasa a ser un discurso que compite en el "mercado de los símbolos", especializando sus funciones y sus mecanismos de legitimación... (Beriain 1990: 96).

En una América Latina caracterizada por situaciones de crisis (Carozzi 1993, 2006), contextos de represión y precariedad material, la movilización social habría utilizado el lenguaje y puesta en escena religiosa como estrategia de protesta. Ejemplos emblemáticos de esta situación constituyeron las agrupaciones pro defensa de los derechos humanos durante las dictaduras latinoamericanas de las década de los 70 y 80 .

Otra relación que Carozzi (2006) explora es la posibilidad que exista, por parte de los movimientos sociales, una sacralización de sus causas (defensa de los derechos humanos, erradicación de la pobreza, promoción de una sociedad igualitaria, etc.), caracterizada por:

[...] los sentimientos optimistas que emergen de la convicción de que finalmente el bien triunfará sobre el mal; la inmersión "efervescente" en las actividades del movimiento que celebra su unidad y su propósito o una visión espiritualizada de la situación que el movimiento busca alcanzar... (Carozzi 2006: 16).

No obstante, nuestra investigación va más allá de los aspectos comunes que pueden tener movimientos sociales y religiosos. La pregunta por la búsqueda de respuestas 
frente a problemáticas sociales concretas es central, pues nuestro interés radica en comprender como las demandas sociales de diversos colectivos van siendo capturadas por agrupaciones religiosas. Es así como desarrollan estrategias resolutivas para enfrentar problemáticas sociales donde se funden los marcos interpretativos de movimientos sociales y religiosos, a través de la resignificación que estos últimos realizan de su función transformadora (Carozzi 1998). Esta mirada intenta revalorizar el rol de lo religioso en la vida pública como agente transformador de la sociedad. A modo de ejemplo, el destacado investigador Craig Colhoun, ha señalado que la reforma protestante del siglo XVI podría ser considerada como el primer movimiento social de la historia (Ramírez 2014), desafiando autoridades, ejerciendo demandas y cuestionando un sistema que iba más allá de lo alcances religiosos, integrando aspectos políticos, culturales y económicos.

Estamos frente a los que Castells (2013) diagnosticaba como un escenario confuso, donde surgen nuevas contradicciones sociales cotidianas que buscan ser combatidas por agrupaciones urbanas que cuestionan el orden establecido. Estas demandas van desde el acceso a servicios básicos (salud, educación, vivienda, etc.) hasta la carencia de espacios recreativos en la ciudad.

\section{LA ALTERNATIVA HARE KRISHNA EN UN ESCENARIO DE CONFLICTOS SOCIALES}

Rochford (2000) al momento de analizar el desarrollo y consolidación del movimiento Hare Krishna en Norteamérica y Europa, da cuenta de un alto sentido de arraigo y pertenencia al conformar una comunidad integrada y solidaria. No obstante, la existencia de límites que separaban al mundo (la sociedad) del colectivo religioso, evidencia una agrupación que intragrupalmente, en sus inicios, poseía un fuerte sentido de asociatividad y, por contrapartida, extragrupalmente se presentaba como aislacionista. De esta forma, y de acuerdo al planteamiento de Squarcini (2000), el movimiento Hare Krishna en los Estados Unidos de la década de los 60' proponía una realidad dual que reforzaba esta división entre la comunidad y la sociedad al plantear que lo exterior significaba lo malo, demoniaco y mundano, y la vida al interior de ésta lo bueno, sacro y espiritual. Esto otorgaba especial valoración a aquellos seguidores que dejaban completamente la vida secular para dedicarse íntegramente al movimiento, renunciando a sus trabajos habituales para vivir en comunidad.

La constitución del movimiento Hare Krishna en occidente estuvo mediada por un contexto sociopolítico convulsionado durante los años 60'. Según narra Satsvarupa Dasa Goswami (1986), los primeros años de Srila Prabhupada ${ }^{5}$ en Norteamérica estuvieron marcados por la precariedad material y la incertidumbre del destino en la misión encomendada, al punto que a sólo meses después de migrar desde la India se vio así mismo en medio del apogeo del movimiento bippie de la época. Artistas, músicos e intelectuales, se mezclaban con el grueso de los marginados de la clase media americana que buscaba vivir la libertad bohemia como una forma de protesta contra el materialismo, el armamentismo, el consumo y la falsa felicidad que exponían los medios de comunicación. Eran abiertos al orientalismo y a la búsqueda de nuevas

\footnotetext{
${ }^{5}$ Líder religioso fundador de la Sociedad Internacional para la Conciencia de Krishna (ISKCON).
} 
experiencias que los guiaran a sintetizar formas de iluminación al margen de lo dictado por el establishment, constituyendo la base de las movilizaciones sociales (estudiantiles, feministas, pacifistas, etc.) y pugnas ideológicas, que significaron un aliciente para que el movimiento Hare Krishna fuese visto como una institución contracultural (Ketola 2004; Dein y Barlow 1999). Este era precisamente el objetivo de Prabhupada, quien luego de ver el inconformismo de la juventud en "la tierra de las oportunidades", situó las bases del movimiento para la conciencia de Krishna, "para educar a la gente en los principios esenciales de la vida espiritual. No se trata de un movimiento religioso sectario. Es un movimiento cultural para el beneficio de todos" (Srila Prabhupada 1997:3).

$\mathrm{Al}$ alero de la juventud disconforme e imbuida en la cultura americana (Vallverdú 2001) su doctrina se expandió por el resto del continente, aunque sin la masividad que logró en ciertos sectores de EE.UU. Para la década de los 80', Rochford (2000) sostiene que se produjo un cambio en la manera de organización de las comunidades Hare Krishnas, en relación a su forma de subsistencia, abriéndose paso a la venta de arte, velas y cds de música, generando un quiebre en la percepción tradicional que los identificaba como una agrupación aislacionista y sectaria dando paso a un proceso de inserción en la sociedad, a través de diversas actividades proselitistas que tenían como objetivo realizar una traducción cultural (Haddon 2013) para dar a conocer su sistema de creencias. Muestra de ello fue la eliminación terminológica de manera progresiva que internamente marcaba una distancia entre aquellos miembros que vivían en la comunidad denominándolos como devotos y aquellos que se encontraba fuera de ésta como no devotos. En la actualidad, fue suprimida esta última siendo utilizada solo la de devotos.

Tras la muerte de Prabhupada en 1977, ISKCON continuó siendo administrado por la Comisión de Cuerpo Gubernamental (GBC), instancia conformada por treinta y dos miembros quienes son responsables de supervisar los aspectos administrativos y espirituales de los centros de a través del mundo, así como velar por su desarrollo mediante proyectos y nuevas iniciativas (Vallverdú 1998). Entre sus objetivos destacan 7 propósitos:

1. Propagar sistemáticamente el conocimiento espiritual en toda la sociedad, y educar a la gente en las técnicas de la vida espiritual, para detener el desequilibrio de valores de la vida, y alcanzar la unidad y la paz verdaderas en el mundo.

2. Propagar la conciencia de Krishna, tal como está revelada en el Bhagavad-gita y el Srimad Bhagavatam.

3. Reunir a los miembros de la Asociación entre si y acercarlos a Krishna, la entidad primordial, y así, desarrollar la idea entre los miembros y la humanidad en general, de que cada alma es parte integrante de la naturaleza de Dios (Krishna).

4. Enseñar y alentar el movimiento de Sankirtan, el canto en congregación del Santo Nombre de Dios, tal como se ha revelado en las enseñanzas de Sri Chaitanya Mahaprabhu.

5. Erigir para los miembros y para la sociedad en general, un lugar santo de pasatiempos trascendentales, dedicado a la Personalidad de Krishna.

6. Unir más a los miembros, con la intención de enseñar una forma de vida más simple y natural.

7. Con el fin de lograr los mencionados objetivos, publicar y distribuir periódicos y revistas. 
Siguiendo el mandato que al morir Prabhupada propusiera a sus seguidores, consistente en expandir las enseñanzas de Krishna a través del movimiento ISKCON, llegan a Chile provenientes de Argentina los primeros devotos discípulos de Prabhupada en 1976. Al año siguiente se instalan en un departamento en Santiago y tras largos años logran fundar el tempo principal de ISKCON en Chile en 1992 en el centro de la ciudad (Quintana 2011; Carnevali 2009). En la actualidad según datos informales el número de devotos rondaría las 2000 personas a nivel nacional, con sedes en Barrio República, Maipú, Nuñoa, Pucón y Coyhaique (Ávila 2013).

Los procesos de conversión de las primeras comunidades Hare Krishnas en Chile estuvieron marcados por una fuerte adscripción a los marcadores culturales de lo que se estimaba correspondía a una forma de vida oriental. La adopción de las vestimentas, el corte del cabello y las pinturas en los rostros, se acompañaban de una estricta dieta vegetariana, la negación de la sexualidad y el enclaustramiento en los templos. De esta forma se constituía una especie de renuncia tanto a los vínculos sociales de origen (familia, escuelas, amigos de barrio, etc.), así como a todo aquello que tuviera relación con la cultura occidental imperante (Vallverdú 1999). Una devota del templo de Santiago concuerda con esto cuando afirma que,

... antes era así, yo creo que hasta los años noventa era así. Los devotos vivían en el templo. Bueno igual este movimiento es súper nuevo en Chile y ahí fue cuando los devotos lo dejaban todo y se dedicaban al templo y se escribieron como las bases del movimiento, como por esos devotos que dieron todo ${ }^{6}$.

La cultura védica se transforma así en un espacio de refugio para estos pequeños grupos de jóvenes que en términos estéticos y simbólicos se encontraban en un país dictatorial marcado por la tensión existente entre la limpieza cultural del pasado marxista, la militarización de la apariencia física y el ensalzamiento del patrimonio nacional y la chilenidad (Errázuriz 2009). Tanto su condición de minoría religiosa, su discurso apolítico y escaza participación pública, lograron hacer de estas comunidades un fenómeno casi imperceptible para las autoridades de gobierno durante la dictadura de Pinochet, situación muy diferente a la que vivían los devotos en Argentina (Ávila 2013).

Este modelo de pertenencia al movimiento Hare Krishna anclado en el ascetismo y la renuncia del mundo ha ido retrocediendo con el transcurso de las décadas. Compartida por todos los entrevistados es la opinión de que la participación activa y reconocida dentro del movimiento actual no pasa necesariamente por practicar un aislamiento social radical. Ciertamente el despertar que propone la filosofía védica implica generar una distancia con prácticas instaladas en la sociedad moderna que se consideran como erróneas o nocivas. No obstante, la promoción de un ideal de devoto que actúe desde dichos principios religiosos en realidades seculares, como la propia familia o el círculo laboral, es profundamente valorada (Rochford 1995). Frente a dicha situación un predicador del templo de Santiago sostiene que, "son pocas las personas que viven en los templos por razón de que la mayoría son jefes de familia. Tienes un desenvolvimiento económico como jefe de familia y tienes un hogar ${ }^{7}$. La

\footnotetext{
${ }^{6}$ Devota 2, periodista, entrevista realizada año 2014, Santiago de Chile.

7 Devoto 3, educador, entrevista realizada año 2014, Santiago de Chile.
} 
mayor parte de las personas que transita dentro de los templos krishnas en la actualidad son jóvenes y adultos estudiantes o trabajadores, en su mayoría profesionales, o como menciona uno de los devotos entrevistados, "el que se acerca ahora más, es el joven educado y no es tanto el hippie botado que está en la calle ${ }^{8}$.

El cambio en las características que posee el devoto promedio genera importantes variaciones al interior del movimiento. La diversidad en las trayectorias de los fieles crece y con ello se flexibilizan los niveles de participación y el tipo de discurso propugnado. Mientras los menos se inician como residentes en las comunidades, el resto decide llevar la ritualidad y los principios de acuerdo a las posibilidades e intereses que posea. La figura del simpatizante, como de quien celebra las fiestas, asiste a charlas o cursos y canta el mantra se hace recurrente. De igual manera, muchos de ellos deciden llevar adelante los cuatro principios fundamentales de manera rigurosa y buscan iniciarse espiritualmente, aunque sin renunciar a su trabajo, familia o pasatiempos. Se construye así una forma de vivir la espiritualidad y la religión marcada por la transitoriedad, la ductilidad y la volatilidad (Lenoir 2005; Champion 1995; VegaCenteno 1995). Tal como menciona uno de los líderes de la comunidad,

Creo que es un aporte bastante significativo porque nosotros le damos todas las herramientas para que las personas, desde sus propios hogares, puedan practicar este proceso, no tengan que ir a un templo. Así que es muy práctico en ese sentido. Hay muchos devotos que van a la universidad, que tienen sus trabajos, sus profesiones, son jefes de familia y su vida está basada en practicar esta conciencia de Krishna desde sus hogares?.

El discurso religioso se transforma y reorienta hacia el krishnaizar la sociedad y el mundo en el que se vive. La constitución de un creyente activo que se desarrolle con éxito dentro de los ámbitos seculares se vuelve un objetivo central. "La predica es insértate en el mundo pero con conciencia espiritual, eso es lo que tratan de difundir los maestros espirituales en general ${ }^{10}$, afirma una de las devotas entrevistadas que se desempeña como relacionadora pública y comunicacional del templo. En su experiencia, tal como la de otros entrevistados, la formación universitaria y el trabajo profesional no implican una limitante en el desarrollo del camino espiritual establecido en los textos milenarios. De acuerdo con esto, la renuncia del devoto de hoy no pasa por dejar su vida anterior en forma abrupta y fanática (considerado esto como falsa renuncia en la tradición védica), sino más bien ocupar los talentos y posiciones de influencia al servicio de Krishna. La renuncia interna sustituye a la externa y permite la expansión del pensamiento vaisnava en contextos que tradicionalmente se presentaban como inaccesibles.

El afianzamiento de una nueva forma de devoto que adapta su participación y compromiso religioso según sus propias necesidades, posibilita la emergencia de nuevos sistemas simbólicos que interpelan la realidad que viven los individuos. Como creyente inmerso en las dinámicas mundanas, la interpretación de las condiciones de la vida propia y de la sociedad que se habita, desde su la perspectiva espiritual, se vuelve primordial en el proceso de crecimiento de la comunidad religiosa. Al igual

\footnotetext{
${ }^{8}$ Devoto 1, profesor de música, entrevista realizada año 2014, Santiago de Chile.

9 Devoto 4, empresario, entrevista realizada año 2014, Santiago de Chile.

${ }^{10}$ Devota 2 .
} 
como realizan otras agrupaciones religiosas, el devoto o simpatizante Hare Krishna genera una lectura de la contingencia y las problemáticas sociales desde las categorías y valores que su cosmovisión entrega.

Al momento de realizar juicios respecto de la realidad social en que se hallan inmersos, los entrevistados concuerdan en que nos encontramos en un periodo de crisis cuyas causas rebasan los límites de la contingencia política y económica. Los problemas sociales son también problemas espirituales, hecho que explicaría la incapacidad de resolverlos apelando solamente a los argumentos de la razón técnica. Difundida entre estos grupos es la idea de vivir inmersos en una decadencia espiritual o falta de espiritualidad que catalizaría los padecimientos sufridos en distintos niveles. Las leyes del karma operarían en la reproducción de un mal que los occidentales, independientes de su condición cultural, política o religiosa, no pueden lograr apagar.

Siguiendo los planteamientos de Srila Prabhupada, una de nuestras entrevistadas afirma que de acuerdo con la tradición vaisnava es posible afirmar que la era que presenciamos se caracteriza por una inclinación a la falta de vida espiritual de los individuos y las consecuencias que eso conlleva. Por miles de años los conflictos sociales y bélicos que se han dado entre los grupos humanos acumularían una violencia histórica que se reproduce generacionalmente en la forma de mal karma. De esta manera, quienes en un momento son víctimas, con el andar de los tiempos se transforman en victimarios que explotan y oprimen desde la condición de ignorancia espiritual que poseen. Tal como explica la entrevistada aludida,

... la poca vida espiritual de las personas está relacionado con las guerras y con los ánimos de agitación en general, porque yo pienso que es como algo karmático lo que sucede en el mundo, porque hay un grupo humano que sufre por otro grupo humano, por ejemplo, los judíos sufren por los nazis, y después los judíos hacen sufrir a los palestinos ${ }^{11}$.

De esta manera, toda forma de reacción traducida en movilización social frente a una percepción de injusticia o arbitrariedad se encuentra incompleta si no se logra comprender la verdad espiritual que subyace a la situación. El líder principal de la agrupación de Santiago de Chile sintetiza esta idea de la siguiente forma: "En realidad, el mundo y el planeta está produciendo todo tipo de granos, frutas, vegetales, o sea no hay escasez, únicamente escasez de conciencia de Dios" ${ }^{12}$.

Tal como lo hiciera Srila Prabhubada en su primer contacto con América, los Hare Krishna no se inclinan por una determinada forma ideológica o política, al punto que incluso la democracia liberal occidental les resulta sospechosa. En los análisis que los propios individuos realizaron respecto de la situación actual de la sociedad chilena, la crítica a las limitaciones espirituales de los líderes y autoridades resulta evidente y compartida. Incluso el sistema védico, afirman, que descansaba sobre una organización de tipo monárquica lograba aceptables niveles de justicia y paz social debido a la santidad del rey, quien por sobre todas las cosas debía comprender las leyes del karma y buscar la felicidad de la población por sobre la propia. Sin importar el sistema político que se privilegie, este nunca logrará ser benevolente con todos si quie-

\footnotetext{
11 Devota 2.

12 Devoto 4.
} 
nes administran el poder no poseen la cualificación espiritual adecuada. La analogía que hace referencia al cuerpo social como un cuerpo sin cabeza, que se manifiesta, adolece y reacciona, son habituales, de ahí que la movilización social no tiene sentido si no se hace desde la conciencia espiritual. Una de nuestras entrevistadas expone este argumento con claridad al afirmar: "yo encuentro que está bien que haya manifestaciones para que el cuerpo se fortalezca, pero igual va a ser un cuerpo sin cabeza ${ }^{13}$.

La crítica a los sistemas políticos y sociales modernos desde la valoración ética propia de las religiones no es del todo algo novedoso. No obstante, lo distintivo que ha sido posible observar a partir de la realidad de las comunidades Hare Krishnas de Santiago es la cercanía que poseen con las demandas y necesidades que impulsan las organizaciones ciudadanas seculares. Tanto la utilización responsable de los recursos naturales, la defensa de los derechos de los animales, la crítica al consumo exacerbado, las formas de discriminación y explotación, la mercantilización de la salud y la educación, entre otros, adquieren centralidad en el discurso de estas agrupaciones. En este sentido, se muestran a sí mismos como más tolerantes y activos en comparación con otras agrupaciones religiosas que sólo logran movilizar a un segmento minoritario y reactivo frente a determinadas coyunturas (ejemplo, las iglesias evangélicas en contra del matrimonio homosexual). La espiritualidad abre una nueva perspectiva desde la cual analizar los conflictos sociales, hecho que explica el fuerte compromiso que despierta este tipo de religiones en ciertos segmentos de la sociedad. "Lo espiritual te abre más lo ojos todavía, el campo de acción de un ser humano se amplía más cuando te haces más espiritual»" ${ }^{14}$, explica el encargado de comunicaciones del templo de Santiago al abordar las diferencias existentes entre quienes poseen un conocimiento interior más profundo y aquellos que no.

Al igual que otras tradiciones religiosas que sostienen la primacía de lo espiritual por sobre lo material y terrenal, el movimiento Hare Krishna promueve el despertar de la conciencia a través del conocimiento de las profundas verdades de la filosofía védica, aunque en un lenguaje accesible y pragmático. Ello resulta de gran atractivo para individuos que se encuentran en un proceso de búsqueda religiosa al margen de los espacios facilitados por las instituciones más tradicionales.

Los movimientos como Hare Krishna entregan vida espiritual a las personas, y la entregan de una manera seria y fidedigna, no entregan cualquier cosa, entregan algo que es científico y que está comprobado. Entonces la gente que está en busca de vida espiritual puede venir acá y satisfacer sus necesidades ${ }^{15}$.

La diversidad interna sobrepasa los límites de la formación profesional o el desempeño laboral, alcanzando el origen socioeconómico y la orientación política individual. Mientras el comportamiento o las convicciones personales no contradigan los cuatro pilares fundamentales que se exigen a todo devoto, la comunidad Hare Krishna de Santiago resulta ser bastante diversa e inclusiva. La presencia de devotos de derecha o izquierda en el ámbito político es común, aunque la tendencia es a generar un

\footnotetext{
13 Devota 2.

${ }_{14}$ Devoto 1.

15 Devota 2.
} 
discurso crítico frente al sistema socioeconómico imperante. Un devoto resulta clarificador al respecto cuando menciona que,

... de alguna forma gran parte de los problemas sociales vienen del sistema. Entonces cuando una persona quiere dejar de experimentar los problemas de la mala salud, de la mala alimentación, de la mala educación, no te queda otra que zafarte del sistema desde lo espiritual, pero obviamente que el hombre siempre funciona en el sistema, en un sistema. Las abejas, las hormigas tienen un sistema de vida. No es que el devoto se sale del sistema y queda asistémico y no hace nada, sino que el devoto tiene una alternativa y eso es lo que plantea Prabhupada, que los devotos tienen que aprender a hacer ${ }^{16}$.

Durante las distintas entrevistas realizadas, las referencias a los mecanismos de explotación humana o natural, así como el abuso de poder por parte de las autoridades, fueron recurrentes aun cuando no se realizarán desde una matriz teórica o ideológica particular. Esto último se condice con la tendencia general a desconfiar del ejercicio político partidista tradicional que califican en general de poco ético y en poca sintonía con los intereses de las personas. Es más, muchos de los individuos que participan de las actividades dentro del templo de Santiago reconocen haber integrado algún tipo de organización con intereses políticos de la cual dicen sentirse defraudados.

Lejos de renunciar a las inquietudes políticas y ciudadanas instaladas en la opinión pública, el movimiento Hare Krishna en Chile se posiciona activa y materialmente dentro del escenario social. En otras palabras, dicha interpretación religiosa de la realidad no se agota en el plano discursivo o ideológico, sino que orienta caminos de acción concretos frente a necesidades y anhelos que resultan compartidos con el resto del cuerpo social. Sin embargo, reconocen que aunque las demandas que han instalado en la agenda pública los movimientos sociales pueden ser sensatas y legítimas, la inconsistencia entre discurso y práctica de quienes participan habitualmente de las manifestaciones públicas suele ser un punto que distancia a los devotos de otros agentes sociales movilizados. Como menciona uno de los devotos del templo de Santiago:

Los chicos que van a las protestas, al mismo tiempo que están reclamando por el capitalismo o el sistema neoliberal, están comprando cigarros, están comprando copete, o sea ¿qué están haciendo? Están alimentando a todas esas empresas por las que ellos mismos están reclamando, no hay una consistencia en el actuar y en el discurso ${ }^{17}$.

Una de las formas más recurrentes de manifestación ciudadana que utilizan los movimientos sociales son las expresiones en el espacio público mediante marchas, protestas, performances o actividades culturales. Movimientos regionalistas, sindicales, ecologistas, educacionales, de diversidad sexual, entre otros, periódicamente muestran la fuerza de su adhesión mediante convocatorias masivas en las calles de Santiago y el resto de Chile, como forma de visibilidad frente a las autoridades políticas, los medios de comunicación y el resto de la ciudadanía. No obstante, en más de una ocasión dichas actividades han acabado en desmanes y destrozos contra la propiedad privada e inmobiliario público, situación que ha generado un rechazo por parte

\footnotetext{
${ }^{16}$ Devoto 1.

${ }^{17}$ Devoto 5, Abogado, entrevista realizada año 2015, Santiago de Chile.
} 
de algunos sectores políticos y sociales, así como la criminalización de la protesta social (Figueroa 2013). Esta situación genera una distancia entre los miembros de las comunidades Hare Krishna de Santiago respecto de la participación en convocatorias realizadas por otros actores sociales debido a que, «en esta línea no nos involucramos con la política, tratamos de tener una propuesta política, una propuesta de cambio, digámoslo una propuesta de revolución de conciencia, pero no nos enganchamos mucho con cosas más subversivas" ${ }^{18}$.

Como es posible observar en los testimonios, los devotos Hare Krishna demuestran poseer conciencia y discurso político, más no concurren activa y oficialmente en manifestaciones masivas convocadas por otros sectores sociales. Cuando se consulta por las razones de aquello, las diferencias se establecen al considerar la violencia que se expresa en las manifestaciones, así como la inconsistencia ideológica producida por la omisión de la dimensión espiritual por parte de los movimientos políticos y sociales actuales. Reconocen la importancia moral que poseen las marchas e intervenciones realizadas en favor de la educación gratuita o aquellas en contra de proyectos que amenazan el medio ambiente, sin embargo, no existe una política oficial desde los templos Hare Krishna para participar o contribuir en su organización y/o desarrollo. A pesar de ello, reconocen la existencia de devotos que han participado de aquellas instancias, aunque siempre de manera particular y con el espíritu de contribuir a generar un ambiente pacífico y de contenido espiritual ${ }^{19}$.

Por otra parte, la no participación en marchas o convocatorias masivas no implican que dentro del movimiento no existan estrategias de impacto social profundamente valoradas. Entre ella encontramos actividades de intervención en espacios públicos o instituciones, estatales o privadas, que sirven de plataforma en la difusión de su mensaje espiritual, a la vez que permiten abordar algunas problemáticas sociales. En ambos casos, la misión de predicación adquiere la forma de asistencia social y de difusión del mensaje político traducido en clave religiosa.

La intervención en espacios públicos es una de las manifestaciones más visibles que llevan a cabo las comunidades Hare Krishna dentro del Gran Santiago. Sustentada en la importancia de llevar la "verdad" del conocimiento vaisnava al resto de la sociedad, los devotos utilizan importantes mecanismos de conexión con el vecindario y el resto de la ciudad. El más importante, que sirve como forma de atracción y servicio, es la difusión de la alimentación sana por medio de la promoción del no consumo de carne animal, utilizando para dicho fin restaurantes y cocinerías ubicadas dentro de los templos, y en las cuales los devotos dan muestras de su variada y exótica alimentación donde sabores y combinaciones nuevas congregan a personas que buscan los beneficios de la comida con misericordia. Todo ello se lleva a la práctica desde el compartir pequeñas porciones con los visitantes durante la ejecución de

\footnotetext{
${ }^{18}$ Devoto 5.

19 Conocidas son las intervenciones de movimientos de raíz Hare Krishna que participan en manifestaciones en favor de los derechos de los pueblos indígenas, en contra de proyectos energéticos o en favor de los derechos de los animales. Sin embargo, los entrevistados del templo de Santiago de Chile afirman que dichos grupos no corresponden a ISKCON Chile, aunque ponderan positivamente los motivos que articulan a estas manifestaciones. Una muestra de esta forma de participación política y cultural se puede ver en el siguiente registro audiovisual: https://www.youtube.com/watch?v=PbzJGJ2vOow (consultado el 19 de julio de 2015).
} 
servicios religiosos, hasta la venta de menús durante el horario de almuerzo en los salones del templo. Esta última actividad constituye una importante manera de recaudación para las necesidades del templo. No obstante, el expendio de comidas y bebidas "Sagradas" ${ }^{20}$ también se lleva a cabo fuera de los límites de la comunidad, realizando con frecuencia entregas de alimentos en sectores que agrupan población en estado de indigencia (Cercanías del Río Mapocho y Estación Central, entre otros). Esta es una parte central del llamado programa Food For Life que busca subsanar necesidades inmediatas de la gente carenciada y dar a conocer la importancia que posee la alimentación con el cultivo de la espiritualidad.

Otra forma de acercamiento de las agrupaciones Hare Krishna hacia la ciudadanía dentro del espacio público lo constituye el Harinam o canto congregacional, el cual lleva a los devotos a cantar y bailar en las calles con el objetivo de "cambiarle el día a las personas, sacarles una sonrisa, que los que están estresados puedan relajarse un poco ${ }^{21}$. Esta actividad, posible de ver en paseos peatonales o plazas públicas, se acompaña de entrega de literatura vaisnava, recetas de cocina vegetariana, música de la India, coloridos bailes y cantos reiterativos. En su propia valoración, los entrevistados reconocen en el Harinam una de las instancias más importantes en su objetivo de romper con los prejuicios y estigmas que acarrean (vinculación con el fanatismo religioso, el hipismo y la drogadicción), e invitar a los transeúntes a participar de las actividades del templo.

No obstante, el Harinam no es la única instancia de manifestación pública que poseen los devotos de Santiago. El Ratha Yatra o Festival de Las Carrozas, en el cual las deidades salen a pasear por la ciudad en carruajes repartiendo misericordia y bendiciones, representa, en voz del encargado de cultura del templo, el evento religioso y cultural más impactante dentro del calendario de las comunidades Hare Krishna. En ella se producen verdaderas manifestaciones sociales, las cuales los devotos homologan en impacto y sentido a cualquier marcha organizada por agrupaciones de la sociedad civil. Un devoto expresa esto al afirmar:

[RathaYatra] es como una marcha, exactamente como una marcha anti sistémica, una marcha que propone una revolución de conciencia, una marcha total pero no con esas características violentas, no con esas características de destrucción, sino que es constructiva, pero yo te digo que es una marcha absolutamente, es anti sistémica y de revolución por un cambio de conciencia ${ }^{22}$.

Para los devotos entrevistados, estas manifestaciones de conciencia Krishna resultan revolucionarias tanto por la fuerza estética que presentan (bailes, músicas y cantos), como por el mensaje radical que poseen. El cambio ético y espiritual propuesto se traduce en prácticas orientadas a superar flagelos como el alcoholismo, tabaquismo, obesidad, delincuencia, estrés y drogadicción. En este sentido, como menciona uno de los devotos, "hay un plan que si tú lo piensas se alinea mucho con las políticas gubernamentales ${ }^{23}$.

\footnotetext{
${ }^{20}$ Todos los procedimientos de cocina dentro del templo están cargados de ritualidad y sentido religioso según las normas establecidas en la religión.

21 Devoto 3.

22 Devoto 5.

23 Devoto 3.
} 
Otra vía de intervención social significativa de las comunidades Hare Krishna de Santiago son aquellas que realizan mediante instituciones públicas y privadas. Esta modalidad representa el fenómeno más reciente en lo que respecta a vinculación con el medio externo a la comunidad, siendo su impacto importante según la institución que promueva las iniciativas propuestas por los integrantes del templo. Algunas de ellas poseen claramente un fin de difusión cultural y religioso, tal es el caso de las intervenciones que realizan en universidades, charlas inter religiosas o centros culturales que buscan rescatar la filosofía védica o la música hindú. Esta última es cultivada a gran nivel por estudiantes de música con estudios en la ejecución de instrumentos tradicionales de la India. La presentación en escenarios del ambiente musical santiaguino, así como la grabación de discos de manera profesional, son consideradas como importantes logros en la difusión de la cultura krishnaista.

No obstante, de mayor alcance social resultan aquellas iniciativas que buscan interceder con fines benéficos en instituciones de asistencia o reclusión. Como menciona uno de los devotos entrevistados, múltiples han sido las instituciones que han acogido las iniciativas elaboradas por los Hare Krishna:

Se han hecho varios programas en cárceles, en hospitales, en manicomios, en hogares de ancianos, pero no solamente a nivel de personas que tienen una carencia económica, sino también en lugares que tienen altísimo poder económico. [...] Vamos a todas parte a mostrar este conocimiento a través de la música, a través de las expresiones culturales, llevamos alimento, llevamos libros ${ }^{24}$.

De acuerdo a lo relatado por los entrevistados, la participación de los internos de estas instituciones siempre ha sido positiva frente a los "atractivos" ${ }^{25}$ que comparten los devotos con ellos, generalmente traducidos en un mensaje espiritual acompañado de comidas tradicionales, bailarines y música en vivo. Frente a escenarios de hostilidad, como el interior de una prisión de alta seguridad o una fundación para enfermos con Síndrome de Down, las iniciativas coordinadas desde los templos se han hecho recurrentes aunque no han alcanzado los niveles de asistencia espiritual de las tradicionales iglesias cristianas. No obstante, lo interesante de recalcar es la apertura hacia canales de movilización poco explorados como son las instituciones de asistencia y los fondos concursables, estos últimos constituyen un terreno que sólo en la actualidad se está vislumbrando de manera incipiente y en vista de las limitaciones que poseen las tradicionales formas de financiamiento, la mayor parte de ellas vinculadas a la donación personal o la recaudación mediante actividades dentro del templo. Un devoto del templo de Santiago nos retrata esta situación con claridad al sostener:

No sabemos muy bien cómo funcionan (los fondos concursables), pero tienes razón en que se necesitan cosas. Fíjate que ahora queremos hacer una intervención en el óvalo de la penitenciaria y son 4000 internos, nos encantaría llevarles algo de comer, llevarles libros. Lo hacemos igual, pero siempre lo hacemos con fondos particulares y eso siempre tiene su límite, te impide llegar a más personas. Sería súper benéfico para nuestro movi-

\footnotetext{
${ }^{24}$ Devoto 5.

25 En más de una ocasión los devotos mencionaron que todo lo ofrendado a Krishna, cuyo significado es posible de entender como el "más atractivo", debe ser realizado con excelencia y dedicación que despierte el encanto en quien lo recibe.
} 
miento que se comience a postular a fondos concursables para hacer intervenciones, es algo bueno, es algo que ayuda a los seres humanos ${ }^{26}$.

Finalmente, importante es destacar que al pretender constituirse como una revolución a nivel de conciencia, el movimiento Hare Krishna chileno aspira a que su crecimiento numérico les permita capturar la adhesión de individuos posicionados en plazas de poder que catalicen importantes cambios en la sociedad. Por ejemplo, afirman, "sería muy bueno que estos devotos llegaran al Congreso Nacional y presentaran proyectos de ley para favorecer iniciativas en favor de los animales ${ }^{27}$. Sin embargo, en todos los casos mencionan que cambios significativos pueden ocurrir incluso en los ambientes más cotidianos, tales como las escuelas, donde muchos de los devotos que se desempeñan como profesores han impulsado iniciativas que promueven la alimentación sana y carente de carne animal.

\section{CONCLUSIONES}

Como hemos podido observar a lo largo de nuestra investigación en la comunidad Hare Krishna de Santiago, la participación religiosa en dicha agrupación se encuentra lejos de significar un alejamiento de los intereses sociales y personales no espirituales de los individuos. Las demandas instaladas por los movimientos sociales de la última década hacen sentido en su particular forma de ver la vida y se acomoda a los canales de acción legitimados por la colectividad. En el plano interno, la promoción de una nueva ética sostenida en los principios regulatorios básicos a todo devoto (vegetarianismo, prohibición del consumo de alcohol y drogas, no practicar el sexo ilícito o comprar juegos de azar) conlleva un cambio personal que impacta en las rutinas y relaciones sociales que se cultivan. De igual forma, la promoción de dichas prácticas con sustrato espiritual lleva a participar de instancias de expresión y difusión en ámbitos visiblemente públicos. La venta de literatura de autoayuda o recetas vegetarianas, la realización de comedores o restaurantes vegetarianos, la realización de carnavales en avenidas concurridas, la generación de talleres gratuitos, la participación en marchas ambientalistas, entre otros, reflejan el compromiso con la realidad social en la que se encuentran inmersos como colectividad. Si a ello sumamos las iniciativas personales y cotidianas con las cuales se busca difundir los principios en los ambientes laborales, podemos afirmar que en tanto agrupación religiosa los Hare Krishna representan una forma de participación ciudadana que supera los principios políticos de la democracia liberal.

De esta forma, cabe destacar que al igual como sucede en otras agrupaciones religiosas que exigen una participación cotidiana intensa dentro de las actividades de la comunidad, los Hare Krishna de Santiago de Chile valoran el sentido de pertenencia que la vida colectiva en torno a la religión les entrega en un contexto donde prima el individualismo y la ética de consumo. Como expresa una de las entrevistadas a partir de su experiencia, "una de las razones por lo que yo me quise quedar en esta comunidad fue porque me trataban súper bien, me gustó el trato, la gente era

\footnotetext{
${ }^{26}$ Devoto 5.

${ }^{27}$ Devoto 5.
} 
cariñosa, amable ${ }^{28}$. Aun cuando no es el objetivo principal de la realización espiritual, los entrevistados afirman que la solidaridad entre los devotos se traduce tanto en apoyo humano como material según las necesidades que existan. "El cuerpo tiene sus necesidades, nuestras emociones o nuestra mente tiene sus necesidades también, y el alma también tiene sus necesidades, nosotros tratamos de balancear esas tres ${ }^{29}$, nos relata el presidente del templo al momento de caracterizar las relaciones internas a la agrupación, y aunque no sea una norma sistematizada, lo cierto es que el apoyo entre los devotos va desde la asistencia monetaria en casos de emergencia, el cuidado de niños, la prestación de servicios o trabajos, el apoyo afectivo, entre otros.

En lo que respecta a las estrategias de movilización, durante el proceso etnográfico y la realización de entrevistas en profundidad fue posible percibir que aun cuando no existe una política central de participación dentro de las manifestaciones públicas organizadas por los actores de la sociedad civil, lo cierto es que en general comparten las motivaciones y excepcionalmente participan a manera personal. No obstante, las modalidades de expresión pública mejor valoradas son aquellas que permiten mostrar el mensaje a la ciudadanía, tales como expendios de comida a los pobres, rituales públicos o festividades, así como aquellas que se encuentran mediatizadas por alguna institución de tipo cultural o benéfica. Es en estas últimas donde mensaje espiritual de consuelo se mezcla con difusión cultural (gastronómica, musical, etc.) en contextos variados y novedosos, abriendo canales de intervención social poco explotados.

Finalmente, cabe destacar que el carácter práctico de los planteamientos de Prabhupada genera que los individuos que se acercan a las comunidades Hare Krishna puedan resignificar el mundo y adaptar los planteamientos a sus propios intereses individuales o sociales. La preocupación por la ecología, la crítica a la modernidad y el consumismo, el hastío con las instituciones políticas, entre otras inquietudes, adquieren valoración e importancia en un relato único que da sentido a la existencia de los sujetos. De esta forma, y siguiendo los postulados de Cristian Parker (2008), el auge de estas creencias heterodoxas, sincréticas y neomágicas entre las capas ilustradas de la sociedad rompe con la antigua creencia que vincula pensamiento progresista con ateísmo. Economistas, periodistas, músicos, profesores, estudiantes universitarios, etc., se desenvuelven en la dualidad de su rutina laboral cotidiana y los vínculos que los unen como devotos dentro del templo, alternando sus nombres espirituales según el momento y el lugar donde se encuentren.

\section{BIBLIOGRAFÍA CITADA}

Augé, Marc. 2000. Los "no lugares". Espacios del anonimato. Una antropología de la sobremodernidad. Barcelona: Gedisa.

Ávila, Constanza. 2013. Crónicas vaisnabas. Una mirada a la filosofía Hare Krishna, Memoria para optar al grado de Periodista, Facultad de Comunicación e Imagen, Universidad de Chile.

Bahamondes, Luis. 2013. "El escenario religioso en el Chile actual: transformación y pluralismo", en Bahamondes, Luis. (ed). Transformaciones y alterativas religiosas en América Latina: 103-118. Santiago de Chile: VDC.

\footnotetext{
${ }^{28}$ Devota 2.

29 Devoto 4.
} 
Bahamondes, Luis. 2012. "Una mirada a la metamorfosis religiosa en América Latina: Nuevas ofertas de sentido en la sociedad contemporánea". Revista Científica Guillermo de Ockham 10 (2): 109116.

Bastian, Jean Pierre. 1997. La mutación religiosa de América Latina. Para una sociología del cambio social en la modernidad periférica. México D.F: Fondo de Cultura Económica.

Beriain, Josetxo. 1990. Representaciones colectivas y proyecto de modernidad. Barcelona: Anthropos.

Cantón, Manuela. 2008. "Los confines de la impostura. Reflexiones sobre el trabajo etnográfico entre minorías religiosas". Revista de Dialectología y Tradiciones Populares LXIII (1): 147-172.

Carnevali, Silvana. 2009. La representación social de los Hare Krishna: miedo, intolerancia y discriminación hacia las minorías religiosas de tipo sectarias. Informe de Seminario de Grado para optar al grado de Licenciatura en Historia, Facultad de Filosofía y Humanidades, Universidad de Chile.

Carozzi, María Julia. 2006. "Otras religiones, otras políticas: algunas relaciones entre movimientos sociales y religiones sin organización central". Ciencias Sociales y Religión8: 11-29.

Carozzi, María Julia. 1998. "El concepto de marco interpretativo en el estudio de los movimientos religiosos". Sociedad y Religión 16/17: 33-59.

Carozzi, María Julia. 1993. "Tendencias en el estudio de los Nuevos Movimientos Religiosos en América: los últimos 20 años". Sociedad y Religión 10/11: 3-31.

Castells, Manuel. 2003. La era de la información. Vol. II: El poder de la identidad. Madrid: Alianza.

Castells, Manuel. 2013. Movimientos sociales urbanos. México: Siglo Veintiuno editores.

Clarke, Peter (ed). 2006. Encyclopedia of new religion movements. Londres: Routledge.

Champion, Françoise. 1995. "Lo religioso flotante, eclecticismo y sincretismos", en Delumeau, Jean. (dir.), El hecho religioso: enciclopedia de las grandes religiones: 709-739. Madrid: Alianza.

Dein, Simon y Barlow, Horace. 1999. "Why do people join the Hare Krishna Movement? Deprivation theory revisited". Mental Health, Religions Culture 2 (1): 75-84.

Dasa Goswami, Satsvarupa. 1986. Prabhupada, Madrid: The Bhaktivedanta Book Trust.

Délano, Manuel. 2004. "Santiago de los extremos", en Délano, Manuel et.al. Nosotros los chilenos/1. Zapping al Chile actual. Mosaico de luces y sombras: 6-27. Santiago: LOM.

Errázuriz, Luis Hernán. 2009. "Dictadura militar en Chile. Antecedentes del golpe estético-cultural". Latin American ResearchReview 44 (2):136-157.

Figueroa, Francisco. 2013. Llegamos para quedarnos. Crónica de una revuelta estudiantil. Santiago de Chile: LOM.

Frigerio, Alejandro. 2003. "PPor nuestros derechos, ahora o nunca!» Construyendo una identidad colectiva umbandista en Argentina". Civitas 3: 35-68.

Garcés, Mario. 2012. El despertar de la sociedad. Los movimientos sociales en América Latina y Chile. Santiago de Chile: LOM.

Gamboa, Andrea. y Puncheira, Iván. 2009. Organizaciones juveniles en Santiago de Chile. Invisibles_ Subterráneas: Santiago de Chile: LOM.

González, Valentina y Quintana, Katia. 2004. "El casado casa quiere”, en Garcés, Mario et. al. Nosotros los chilenos/5. El mundo de las poblaciones: 46-63. Santiago: LOM.

Haddon, Malcolm. 2013. "Anthropological proselytism: Reflexive questions for a Hare Krishna ethnography". The Australian Journal of Anthropology 24: 250-269.

Hobsbawm, Eric. 1999. Historia del siglo XX. Buenos Aires: Crítica.

Ketola, Kimmo. 2004. "The Hare Krishna and the counterculture in the light of the theory of divergent models of religiosity". Method E Theory in the Study of Religion 16: 301-320.

Lalive D'Epinay, Christian. 1968. El refugio de las masas. Santiago de Chile: editorial del PacíficoComunidad Teológica Evangélica.

Larraín, Jorge. 2005. ¿América Latina moderna? Globalización e identidad. Santiago: LOM.

Lenoir, Frédéric. 2005. La metamorfosis de Dios: Nueva espiritualidad occidental. Madrid: Alianza.

Mayol, Alberto. 2012. El derrumbe del modelo: La crisis de la economía de mercado. Santiago: LOM.

Melucci, Alberto. 1999. "¿Qué hay de nuevo en los nuevos movimientos sociales?", en Enrique Laraña y Joseph Gusfield (coords.), Los nuevos movimientos sociales: de la ideología a la identidad: 119150. Madrid: Editorial Istmo.

Ossa, Manuel. 1991. Lo ajeno y lo propio. Identidad pentecostal y trabajo. Santiago: Rehue. 
Parker, Christian. 2005. «América Latina ya no es católica? Pluralismo cultural y religioso creciente». América Latina Hoy 41: 35-56.

Parker, Christian. 2008. "Mentalidad religiosa post-ilustrada: Creencias y esoterismos en una sociedad en mutación cultural", en Alonso, A. (comp.), América Latina y el Caribe. Territorios religiosas y desafíos para el dialogo: 337-364. Buenos Aires: CLACSO.

Prat, Joan. 1997. El estigma del extraño. Un ensayo antropológico sobre sectas religiosas. Barcelona: Ariel.

Pujadas, Joan J. 2000. "El método biográfico y los géneros de la memoria". Revista de Antropología Social 9: 127-158

Quintana, Pamela. 2011.Chilenos convertidos en devotos de krishna: una aproximación al movimiento internacional para la conciencia de krishna en Santiago de Chile. Tesis para Optar al Título de Antropóloga y Grado Académico de Licenciado en Antropología Social, Universidad Bolivariana.

Ramírez, Paulo. 2014. "La sabiduría de las masas". Disponible en: <http://www.quepasa.cl/articulo/ actualidad/2014/08/1-14958-9-la-sabiduria-de-las-masas.shtml>. Fecha de acceso: 20 agosto 2014.

Rochford, E. Burke. 2000. "Demons, Karmies, and Non-devotees: Culture, Group Boundaries, and the Development of Hare Krishna in North America and Europe". Social Compass 47 (2): 169186.

Rochford, E. Burke. 1995. "Family Structure, Commitment, and Involvement in the Hare Krishna Movement. Sociology of Religion 56 (2): 153-175.

Salazar, Gabriel. 2012. Movimientos sociales en Chile. Trayectoria histórica y proyección política. Santiago: Uqbar Editores.

Sautú, Ruth. 2004. "Estilos y prácticas de la investigación biográfica”, en Sautu, R. (comp.), El método biográfico. La reconstrucción de la sociedad a partir del testimonio de los actores: 21-60. Buenos Aires: Editorial Belgrano.

Suárez, Hugo. 2003. "La religión en la sociedad red: la experiencia latinoamericana”, en Calderón, Fernando (coord.) ¿Es sostenible la globalización en América Latina? Debates con Manuel Castells, Tomo II: 101- 125. Santiago de Chile: Fondo de Cultura Económica - PNUD Bolivia.

Squarcini, Federico. 2000. "In search of Identity within the Hare Krisna Movement: Memory, Oblivion and Thought Style». Social Compass 47 (2): 253-271.

Srila Prabhupada. 1997. Preguntas perfectas respuestas perfectas. Madrid: The Bhaktivedanta Book Trust.

Tilly, Charles y Wood, Lesley. 2010. Los movimientos sociales, 1768-2008. Desde sus origenes a Facebook. Barcelona: Crítica.

Touraine, Alain. 1998. Igualdad y diversidad. Las nuevas tareas de la democracia. México D.F: Fondo de Cultura Económica.

Vallverdú, Jaume. 1999. “Conversión, compromiso y construcción de identidad en el movimiento Hare Krisna”. Revista Alteridades 9 (18): 57-70.

Vallverdú, Jaume. 1998. "El movimiento Hare Krishna: precedentes históricos y doctrinales". Ilu. Revista de Ciencias de las religiones 3: 275-303.

Vallverdú, Jaume. 2001. "Movimientos religiosos e identidades juveniles. Hare Krishna en Occidente. Revista de Estudios de Juventud 53(1):57-71.

Vega-Centeno, Imelda 1995. "Sistemas religiosos. Entre la oferta y la demanda simbólicas". Revista Nueva Sociedad 136: 56-69.

Fecha de recepción: 5 de mayo de 2015

Fecha de aprobación: 27 de septiembre de 2015 